American Medical Journal 2 (1): 7-12, 2011

ISSN 1949-0070

(C) 2011 Science Publications

\title{
Thrombophilic Genes Mutations in Women with Repeated In-Vitro Fertilization Failure
}

\author{
${ }^{1}$ Naglaa Fathy Al Husseini, ${ }^{2}$ Ahmad Y. Rezk, ${ }^{1}$ Mosad M. Odah, \\ ${ }^{1}$ Shaymaa M. Abd El Rahman and ${ }^{1}$ Amal Idris Ali \\ ${ }^{1}$ Department of Medical Biochemistry, \\ ${ }^{2}$ Department of Obstetrics and Gynecology, \\ Faculty of Medicine, Benha University, Egypt
}

\begin{abstract}
Problem statement: Thrombophilia has been recently implicated in early pregnancy loss and IVF implantation failure, by impairing the initial vascularization process occurring at implantation, which is necessary for a successful pregnancy. Approach: The aim of this study is to assess the presence possibility of mutation in thrombophilic genes [Factor V (FV) gene, Prothrombin (PT) gene and Methylenetetrahydrofolate Reductase (MTHFR) gene] in women with repeated IVF-embryo transfer failure with unknown causes. The study was performed on patients with two or more previously failed IVF-embryo transfer cycles with unknown causes. Women who conceived spontaneously with no previous history of miscarriage and women who have had successful pregnancy after their first IVF-embryo transfer cycle are included as control groups. Results: There are increase in allelic frequencies of thrombophilic genes (factor $\mathrm{V}$, prothrombin and methylenetetrahydrofolate reductase) mutation, in addition to genotype frequencies (both homozygote and heterozygote) and increase in frequency of multiple gene mutations among women with IVF- embryo transfer failure. Conclusion: Thrombophilia has a significant role in IVF- embryo transfer implantation failure. Women with repeated IVF- embryo transfer failure should be screened for Thrombophilia to avoid repeated IVF- embryo transfer failure.
\end{abstract}

Key words: Thrombophilia-mutation-IVF-multiplex PCR-Reverse hybridization, Recurrent Pregnancy Loss (RPL), Methylenetetrahydrofolate Reductase (MTHFR), Nitro Blue Tetrazolium (NBT), In-Vitro Fertilization (IVF), Intracytoplasmic Sperm Injection (ICSI), Prothrombin (PT), Body Mass Index (BMI), Factor V Ledien (FVL)

\section{INTRODUCTION}

In-Vitro Fertilization and Embryo Transfer (IVFET) is only one method of assisted reproduction that enables couples to turn their dream of having a child into a reality. About one- third of women undergoing will achieve an ongoing pregnancy (Qublan et al., 2005). Failure to achieve pregnancy implies failure of the pregnancy at implantation or at a time shortly thereafter. Several factors have been recognized to affect either success or failure rate of IVF-embryo transfer. Such factors include age, parity, previously successful pregnancy, basal hormonal levels, number of antral follicles before stimulation; endometrial thickness, embryo grading, position and length of uterus and technique of embryo transfer (Qublan et al., 2005).

Thrombophilia is a multifactorial disease, the pathogenesis involving both circumstantial and genetic mechanisms. Circumstantial factors that increase the risk of thrombosis include increasing age, immobilization, surgery, pregnancy, oral contraceptives, hormone replacement and inflammatory conditions (Dahlback, 2008).

Inherited or acquired thrombophilia have been recently implicated in early pregnancy loss and IVF implantation failure, by impairing the initial vascularization process occurring at implantation, which is necessary for a successful pregnancy (Kujovich, 2004). Inherited factors for thrombophilia include mutation in factor V Leiden, prothrombin and Methylenetetrahydrofolate Reductase (MTHFR) genes which are major causes of thromboembolic diseases. Moreover, it may predispose for pregnancy complications with different mechanisms (Agnieszka et al., 2008).

Corresponding Author: Naglaa Fathy Al Husseini, Department of Medical Biochemistry, Faculty of Medicine, Benha University, Egypt 
The known thrombotic nature of the placental lesions and the risk associated with both acquired and genetic thrombophilias strongly suggest a cause-effect relationship between thrombophilias and severe obstetric complications. The evidence of thrombosis or infarcts in the placental sections suggests a haemostatic abnormality with thrombophilia (Vora et al., 2009).

Placental thrombosis may be final common pathophysiologic pathway in most women with habitus abortions and repeated pregnancy wastage Kasparova and Fait (2009). Thrombophilia has a significant role in IVF-embryo transfer implantation failure (Qublan et al., 2006). The aim of this study is to clarify the value of the etiological diagnosis of mutation in thrombophilic genes [Factor V (FV) gene, Prothrombin (PT) gene and Methylenetetrahydrofolate Reductase (MTHFR) gene] in women with repeated IVF- embryo transfer failure with unknown causes.

\section{METERIALS AND METHODS}

This is a comparative cross- sectional observational study that was performed on 60 women divided into two control groups (group A and B) and one patient group C. Group A- included 20 women who conceived spontaneously with no previous history of miscarriage. Group B- included 20 women who have had successful pregnancy after their first IVF-embryo transfer cycle. Group C- included 20 women with two or more previously failed IVF-embryo transfer cycles with unknown causes and attending the IVF Unit of Benha University Hospital between January and June 2009 for undergoing IVF. All the studied groups were age matched. The study was approved by the institutional ethics committee and all subjects signed an informed consent form. Women with endometriosis, hydrosalpinx, abnormal uterine cavity on the hysterosalpingogram, history of thromboembolic diseases and those who receiving hormonal treatment were excluded.

Detection of genotype mutation: All reagents used in these steps provided by HVD Strip Assay kit manufactured by "Viennalab. Diagnostika GmbH"

Blood DNA extraction: DNA was extracted from $100 \mu 1$ blood sample. The extracted DNA concentration was confirmed through measurement by UV Spectrophotometer, readings were taken at wave lengths of 260 and $280 \mathrm{~nm}$. according to that reported by (Al Husseini et al., 2010). The extracted DNA concentration was ranged from 20-30 ng DNA/ $\mu \mathrm{L}$.

Multiplex PCR amplification: Multiplex PCR amplification reaction mixture was prepared for each sample using biotinylated primers with specific sequences for detections of different genotype mutations in the three genes (FVL-PTH and MTHFR).

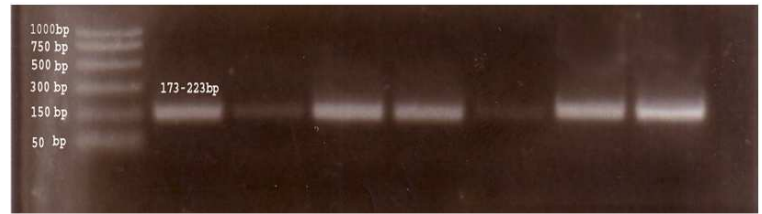

Fig. 1: Gel electrophoeresis of the amplified products of (FVL, prothrombin and MTHFR) genes

In thermalcycler (G-Storm United kingdom) the prepared reaction components were done in conditions of $94^{\circ} \mathrm{C}, 2 \mathrm{~min}$, (Initial denaturation) followed by 35 cycles of $94^{\circ} \mathrm{C}, 15 \mathrm{sec}, 58^{\circ} \mathrm{C}, 30 \mathrm{sec}$ and $72^{\circ} \mathrm{C}, 30 \mathrm{sec}$ for denaturation, annealing, extension steps respectively. The amplified DNA was analyzed by gel electrophoresis. $10 \mu \mathrm{L}$ of each reaction mixture and 1000 bp ladder (molecular weight marker) was separated on $3 \%$ agarose gel contain $0.3 \mu \mathrm{g} / \mathrm{mL}$ of ethidium bromide. The bands of fragment lengths suspected to see at 173, 202, 223 bp indicate successful amplification (Fig. 1).

Reverse hybridization of amplification products: The amplified products were selectively hybridized to stripA $^{\text {ssay }}$ which was containing allele-specific oligonucleotide probes (wild and mutant specific) immobilized as an array of parallel lines, was used instead of using radioactive probe, the bound biotinylated sequences were detected using streptavidin-alkaline phosphatase and color substrates.

In a thermoshaker (Shy line shaker DTS-2) $10 \mu \mathrm{L}$ of each amplification product was used in the typing trays with $1 \mathrm{ml}$ Hybridization Buffer added to a test strip with orbital shaking at $45^{\circ} \mathrm{C}$ for $30 \mathrm{~min}$ at $50 \mathrm{rpm}$ Washing performed at $45^{\circ} \mathrm{C}$ with shaking.

Identification of the hybridized products: Detection of specifically bound mutant and wild type alleles was by visible enzymatic color reaction.

For each test strip, $1 \mathrm{~mL}$ Conjugate Solution (contains streptavidin-alkaline phosphatase) was added and incubated for $15 \mathrm{~min}$. at room temperature. After that $1 \mathrm{ml}$ Color Developer (contains Nitro Blue Tetrazolium (NBT) and 5-bromo-4- chloro-3- indolyl phosphate) was added and Incubated for $15 \mathrm{~min}$. at room temperature in the dark on orbital shaker.

Statistical analysis: The results were presented as means $\pm \mathrm{SD}$, comparisons of categorical variables were made between patient and control groups using chisquare test, student " $t$ " test, F test and the sperman's correlation coefficient were used to measure the closeness of a linear relationship between the results of mutation in thrombophilic genes and the frequency of repeated IVF-embryo transfer cycle. The Statistics Package for Social Sciences (SPSS) and Microsoft 
Office Excel were used for data processing and data analysis. Differences were considered as statistically significant for a $\mathrm{p}$ value less than 0.05 .

\section{RESULTS}

The study results indicated that there are statistically significant higher in the maternal age of patients, as compared to control groups, $(p<0.05)$. However, there is no statistically significant differences in Body Mass Index (BMI) of patients, as compared to control groups, $(\mathrm{p}>0.05)$ (Table1). There are high statistically significant increase of both number of previous (IVF) $(2.9 \pm 0.79)$ and duration of infertility ( $4.6 \pm 2.88$ year $)$ in patients, as compared to $(0.5 \pm 0.51)$ and $(2.5 \pm 2.78$ year $)$ in IVF successful controls (Group B) $\quad(\mathrm{p}<0.001) \quad(\mathrm{p}<0.05)$ respectively with confidence interval 95\% CI (1.97$2.283)$ and (0.28-3.9) respectively.

There are high statistically significant increase in the number of patients with factor $\mathrm{V}$, prothrombin and methylenetetrahydrofolate reductase genes mutation, as compared to control groups, $\mathrm{p}<0.001$ for all (Table 2).

Also there are high statistically significant increase in the number of patients who have mutation either heterozygous or homozygous, single or multiple genes mutation (two or more) in factor $\mathrm{V}$, prothrombin and methylenetetrahydrofolate reductase genes, as compared to control groups, $(\mathrm{p}<0.001)$ (Table 3).

Table 1: Clinical profile of In Vitro Fertilization (IVF) failed patients and control groups (Normal and IVF successful)

\begin{tabular}{|c|c|c|c|c|c|}
\hline \multirow{3}{*}{$\begin{array}{l}\text { Studied groups } \\
\text { Parameters }\end{array}$} & \multicolumn{3}{|l|}{ Control groups } & \multirow{2}{*}{\multicolumn{2}{|c|}{ Patient group }} \\
\hline & \multirow{2}{*}{$\begin{array}{l}\text { Normal } \\
\text { (Group A) }\end{array}$} & \multirow{2}{*}{$\begin{array}{l}\text { IVF successful } \\
\text { (Group B) }\end{array}$} & \multirow{2}{*}{$\begin{array}{l}\text { IVF failure } \\
\text { (Group C) }\end{array}$} & & \\
\hline & & & & $\mathrm{F}$ & $\mathrm{p}$ \\
\hline Number & 20 & 20 & 20 & & \\
\hline No. of patients with repeated IVF failure $=2$ & $0(0.00 \%)$ & $0(0.00 \%)$ & $6(30 \%)$ & & \\
\hline & $0(0.00 \%)$ & $0(0.00 \%)$ & $14(70 \%)$ & & \\
\hline No. of subjects having previous live births & $20 / 20(100 \%)$ & $20 / 20(100 \%)$ & $20-\mathrm{Feb}(10 \%)$ & & \\
\hline History of diseases (Diabetes Mellitus and hypertension) & No $(0 \%)$ & No $(0 \%)$ & No $(0 \%)$ & & \\
\hline Abdominal operations & No $(0 \%)$ & 20-Jan $(5 \%)$ & $20-\operatorname{Mar}(15 \%)$ & & \\
\hline Maternal age & $29.0 \pm 4.87$ & $28.1 \pm 5.04$ & $33.2 \pm 6.52$ & 4.85 & $<0.05^{*}$ \\
\hline BMI & $25.6 \pm 2.6$ & $27.5 \pm 7.75$ & $25.08 \pm 0.77$ & 1.46 & $>0.05$ \\
\hline
\end{tabular}

Table 2: Percentage of allele frequency of factor $\mathrm{V}$, prothrombin and methylenetetrahydrofolate reductase genes mutations among In Vitro Fertilization (IVF) failed patients and control groups (Normal and IVF successful)

\begin{tabular}{|c|c|c|c|c|c|c|c|c|}
\hline \multirow{3}{*}{$\begin{array}{l}\text { Studied groups } \\
\text { Parameters }\end{array}$} & & & \multicolumn{4}{|l|}{ Control groups } & \multirow{2}{*}{\multicolumn{2}{|c|}{ Patient group }} \\
\hline & & & \multirow[b]{2}{*}{ Normal (Group A) } & \multirow{2}{*}{$\begin{array}{l}\text { IVF successful } \\
\text { (Group B) }\end{array}$} & \multirow{2}{*}{ IVF failure } & \multirow[b]{2}{*}{ Total } & & \\
\hline & & & & & & & $\mathrm{X}^{2}$ & $\mathrm{p}$ \\
\hline \multirow{3}{*}{ FV gene } & Number & & 20 & 20 & 20 & 60 & - & - \\
\hline & Normal & No. $(\%)$ & $19(95.00 \%)$ & $19(95.00 \%)$ & $6(30.00 \%)$ & $44(73.30 \%)$ & & \\
\hline & Mutant & No. $(\%)$ & $1(5.00 \%)$ & $1(5.00 \%)$ & $14(70.00 \%)$ & $16(26.70 \%)$ & 28.8 & $<0.001$ \\
\hline \multirow[t]{2}{*}{ PTH gene } & Normal & No. $(\%)$ & $19(95.00 \%)$ & $19(95.00 \%)$ & $7(35.00 \%)$ & $45(75.00 \%)$ & & \\
\hline & Mutant & No. $(\%)$ & $1(5.00 \%)$ & $1(5.00 \%)$ & $13(65.00 \%)$ & $15(25.00 \%)$ & 25.6 & $<0.001$ \\
\hline \multirow[t]{2}{*}{ MTHFR gene } & Normal & No. $(\%)$ & $20(100.00 \%)$ & $19(95.00 \%)$ & $6(30.00 \%)$ & $45(75.00 \%)$ & & \\
\hline & Mutant & No. $(\%)$ & $0(0.00 \%)$ & $1(5.00 \%)$ & $14(70.00 \%)$ & $15(25.00 \%)$ & 32.53 & $<0.001$ \\
\hline
\end{tabular}

$\mathrm{p}<0.001$ : highly Significant $\mathrm{X}^{2}=$ Adjusted Chi

Table 3: Percentage of single and multiple genes mutation among In Vitro Fertilization (IVF) failed patients and control groups (Normal and IVF successful)

\begin{tabular}{|c|c|c|c|c|c|c|c|c|}
\hline \multirow{3}{*}{$\begin{array}{l}\text { Studied groups } \\
\text { Parameters }\end{array}$} & & & \multicolumn{4}{|l|}{ Control groups } & \multirow{2}{*}{\multicolumn{2}{|c|}{ Patient group }} \\
\hline & & & \multirow[b]{2}{*}{ Normal (Group A) } & \multirow{2}{*}{$\begin{array}{l}\text { IVF successful } \\
\text { (Group B) }\end{array}$} & \multirow[b]{2}{*}{ IVF failure } & \multirow[b]{2}{*}{ Total } & & \\
\hline & & & & & & & $X^{2}$ & $\mathrm{p}$ \\
\hline & Number & & 20 & 20 & 20 & 60 & - & - \\
\hline \multirow[t]{3}{*}{ Genotype of FV } & Normal (-/-) & No. $(\%)$ & $19(95.00 \%)$ & $19(95.00 \%)$ & $6(30.00 \%)$ & $44(73.30 \%)$ & & \\
\hline & Heterozygous $(+/-)$ & No. $(\%)$ & $1(5.00 \%)$ & $1(5.00 \%)$ & $11(55.00 \%)$ & $13(21.70 \%)$ & & \\
\hline & Homozygous $(+/+)$ & No. $(\%)$ & $0(0.00 \%)$ & $0(0.00 \%)$ & $3(15.00 \%)$ & $3(5 \%)$ & 29.07 & $<0.001$ \\
\hline \multirow[t]{3}{*}{ Genotype of PTH } & Normal (-/-) & No. $(\%)$ & $19(95.00 \%)$ & $19(95.00 \%)$ & $7(35.00 \%)$ & $45(75.00 \%)$ & & \\
\hline & Heterozygous (+/-) & No. $(\%)$ & $0(0.00 \%)$ & $0(0.00 \%)$ & $7(35.00 \%)$ & $7(11.70 \%)$ & & \\
\hline & Homozygous $(+/+)$ & No. $(\%)$ & $1(5.00 \%)$ & $1(5.00 \%)$ & $6(30.00 \%)$ & $8(13.30 \%)$ & 26.65 & 0 \\
\hline \multirow[t]{3}{*}{ Genotype of MTHFR } & Normal (-/-) & No. $(\%)$ & $20(100.00 \%)$ & $19(95.00 \%)$ & $6(30.00 \%)$ & $45(75.00 \%)$ & & \\
\hline & Heterozygous (+/-) & No. $(\%)$ & $0(0.00 \%)$ & $1(5.00 \%)$ & $9(45.00 \%)$ & $10(16.70 \%)$ & & \\
\hline & Homozygous $(+/+)$ & No. $(\%)$ & $0(0.00 \%)$ & $0(0.00 \%)$ & $5(25.00 \%)$ & $5(8.30 \%)$ & 32.73 & $<0.001$ \\
\hline
\end{tabular}

$\mathrm{p}<0.001$ highly Significant $\mathrm{X}^{2}=$ Adjusted Chi 
Am.Med.J. 2 (1): 7-12, 2011

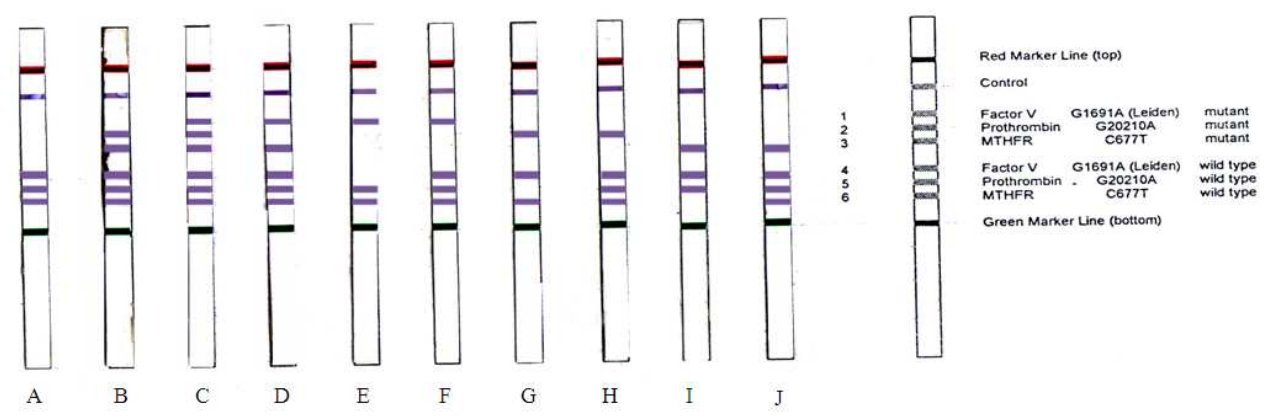

Fig. 2:Homozygous and Heterozygous Mutations of Factor V, Prothrombin and Methylenetetrahydrofolate Reductase Genes

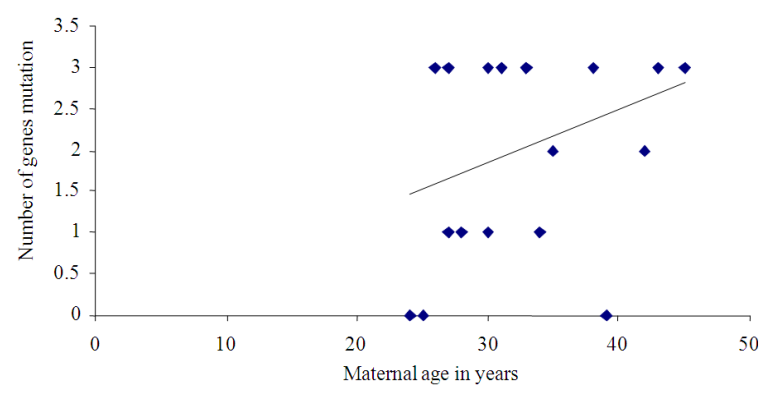

Fig. 3: Correlation coefficient (r) between maternal age and number of genes mutation among In Vitro Fertilization (IVF) failed patients

There are high statistically significant increase in the number of patients with single gene (4/20-20\%) and multiple genes (13/20-65.0\%) mutation, as compared to $(5 / 40-12.5 \%)$ and $(0 / 40-0 \%)$ in control groups, $\mathrm{p}<0.001$ for all Fig. 2

The correlations between maternal age and number of IVF, number of genes mutation and number of In Vitro Fertilization (IVF) failure indicate no statistical significant values ( $p>0.05$ ). (Fig. 3)

There is no statistically significant increase in maternal age and number of In Vitro Fertilization (IVF) failed patients with single and multiple genes mutation, as compared to In Vitro Fertilization (IVF) failed patients with normal genes, $\mathrm{p}>0.05$ for all.

\section{DISCUSSION}

This study showed that the allelic frequency of Factor V Leiden (FVL) in our control groups is (5\%) which was similar with the $4.3 \%$ reported for the population of Greece (Fka et al., 2000).The significant increases of allelic frequency as well as homozygosity and heterozygosity of FVL gene in women with repeated IVF- embryo transfer failure were in agreement with Foka et al. (2000) who documented an association between factor $\mathrm{V}$ Leiden and fetal loss after IVF and demonstrated a 4-fold, 2.2-fold and 4-fold increase correspondingly in the prevalence of factor $\mathrm{V}$ Leiden in women with fetal loss after IVF as compared to controls and were in agreement with those of Grandone et al. (2001), who reported an association between IVF- embryo transfer failure and an increased incidence of thrombophilia. Moreover, Rey et al., (2003) reported that 3-4 fold increased risk of recurrent early pregnancy loss was found in women with FVL mutation. Kujovich (2004) reported that mutation in FVL gene increases thrombin generation, with a 4-8 fold increased risk of thrombosis in the heterozygous mutation and 80-fold increased risk in the homozygous mutation. Also Azem et al. (2004) revealed a high prevalence of thrombophilia in women with repeated IVF- embryo transfer failure as compared with normal women. In addition, Qublan et al. (2006) showed that the prevalence of FVL mutation was higher in women with repeated IVF failure than was found in women with successful IVF-embryo transfer and the healthy controls. Later, Lindhoff-Last and Luxembourg (2008) observed significant associations with early and late pregnancy loss and carriers of the heterozygous factor $\mathrm{V}$ Leiden mutation.

On the other hand, our results disagree with the results of Pauer et al. (1998) who suggested that that factor $\mathrm{V}$ Leiden is not a predisposing factor for recurrent fetal loss after IVF. Furthermore, Gopel et al. (2001) showed higher Intracytoplasmic Sperm Injection (ICSI) success in mother-child pairs with a factor V Leiden, Suggesting that a thrombotic tendency of carriers of the Leiden mutation has some advantage in fetal implantation.

These finding may be explained by Kupferminc et al. (1999) who suggested that thrombosis of maternal vessels and reduced perfusion to the intervillous space may contribute to these complications in association with thrombophilia. Moreover, Azem et al. (2004) 
suggested that invasion of maternal vessels by the syncythiotrobopblast may be affected by local microthrombosis at the site of implantation loading to implantation failure or pregnancy loss/miscarriage.

The significant increase of allelic frequency as well as homozygosity and heterozygosity of PTH gene mutation in women with repeated IVF-embryo transfer failure were in agreement with Foka et al. (2000) who reported that prothrombin G20210A was significantly more common in women with fetal loss after IVF than in controls. Moreover, Rey et al. (2003), reported that mutation in prothrombin gene was associated with a 2to 3-fold increased risk repeated IVF- embryo transfer failure. Recently, Lindhoff-Last and Luxembourg (2008) observed significant associations with early and late pregnancy loss and carriers of the heterozygous prothrombin-mutation G20210A. In the same year, Di Micco et al. (2008) supported that the homozygosis for the FII G20210A variant may be a risk factor also for arterial thrombtic events besides of venous thrombo-embolism. Also the same finding was reported by Mohamed et al. (2010), they reported that there were high statistically significant increases in the number of cases but of repeated spontaneous miscarriage with factor $\mathrm{V}$, prothrombin and methylenetetrahydrofolate reductase gene mutations compared with normal control and the percentage of multiple gene mutations was higher than single gene mutation.

On the other hand Kutteh et al. (1998) did not find any association between prothrombin G20210A polymorphism and fetal losses after IVF.

These finding may be explained by Kujovich, (2004) who reported that elevated plasma prothrombin levels with 2- to 4 fold increased risk of venous thrombosis were found in association with a singlenucleotide substitution (G20210A) in the 3, un translated regions of the prothrombin gene.

In the study of MTHFR, Our finding were consistent with Kutteh et al. (1998) who evaluated the relationship between recurrent early pregnancy loss and hyperhomocystinaemia and the MTHFR C677T mutation .Also, Unfried et al. (2002) who reported that homozygosity for a common C677T mutation in the 5, 10-MTHER gene that was associated with hyperhomocystinaemia leads to a 3 -fold increase in risk for early miscarriages. Recently, Mukhopadhyay et al. (2009) supported the association between MTHFR C677T and patients with early Recurrent Pregnancy Loss (RPL).

These results were controversial the results of, Rey et al. (2003) who suggested that MTHFR may not be important in recurrent miscarriage.

Our data supported by Heby (1995) who reported that elevated maternal plasma homocystine levels were associated with impaired DNA methylation and gene expression that lead to defective chorionic villous vascularization with subsequent early embryonic death.

In the case of multiple genes mutation, our findings were in agreement with those reported by Azem et al. (2004) who showed that at least one thrombophilic factor was detected in women who have had previously two or more IVF-embryo transfer failures. Colman (2006) observed that women with recurrent implantation failure after IVF-embryo transfer had three or more gene mutations compared with healthy fertile controls. Recently, Di Micco et al. (2008) reported that inherited thrombophilia and in particular the prothrombin A20210G variant is relevant risk factor for recurrent pregnancy loss.

\section{CONCLUSION}

There were many possible explanations for our finding. First, all patients in our study were of the same ethnic origin. Differences in the prevalence of thrombotic mutations according to ethnicity are likely to result in various strengths of associations in different populations. Second, strict criteria for selecting patients in our study were applied. All women were apparently healthy with no previous history of thyroid disease, diabetes mellitus or thromboembolic disease (Qublan et al., 2006).

Furthermore, women with endometriosis, hydrosalpinx, abnormal uterine cavity on the hysterosalpingogram and history of thromboembolic disease and those who were receiving hormonal treatment were not included in the study group and only cycles in which grade 1 and 2 embryos were included. Such a selection may be responsible for the increased prevalence of thrombophilia in our study (Qublan et al., 2006).

\section{ACKNOWLEDGMENT}

Special Thanks to Molecular Biology Unit, Faculty of Medicine, Benha University

\section{REFERENCES}

Agnieszka, S.M., D. Krzysztof, P. Piotr and K.S. Agnieszka, 2008. [Inherited thrombophilia in women with recurrent miscarriages and pregnancy loss in anamnesis--own experience]. Ginekol Pol., 79: 630-634. PMID: 18939515

Al Husseini, N.F., M.M. Odaa, M.A. Mohamed, W.B.A. El Wahab and A.A. Hasan, 2010. Expression of adiponectin receptors in human placenta and its possible implication in gestational diabetes. Am. J. Biochem. Biotechnol., 6: 136-140. DOI: 10.3844/ajbbsp.2010.136.140 
Azem, F., A. Many, I. Yovel, A. Amit and J.B. Lessing et al., 2004. Increased rates of thrombophilia in women with repeated IVF failures. Hum Reprod, 19: 368-370. DOI: 10.1093/humrep/deh069

Colman, R.W., 2006. Are homeostasis and thrombosis two sides of the same coin? J. Experim. Med., 203: 493-495. PMID: 16533890

Dahlback, B., 2008. Advances in understanding pathogenic mechanisms of thrombophilic disorders. Blood 112:19-27. DOI: 10.1182/Blood2008-01-077909

Di Micco, P., R. Di Fiore, A. Niglio, S. Quaranta and A. Angiolillo et al., 2008. Different outcome of six homozygotes for prothrombin A20210A gene variant. J. Transl. Med., 6: 36. DOI: 10.1186/14795876-6-36

Gopel, W., M. Ludwig, A.K. Junge, T. Kohlmann and K. Diedrich et al., 2001. Selection pressure for the factor-V-Leiden mutation and embryo implantation. Lancet, 358: 1238-1239. DOI: 10.1016/S0140-6736(01)06354-1

Grandone, E., D. Colaizzo, A. Lo Bue, M.G. Checola and E. Cittadini et al., 2001. Inherited thrombophilia and in vitro fertilization implantation failure. Fertil Steril, 76: 201-202. PMID: 11438344

Heby, O., 1995. DNA methylation and polyamines in embryonic development and cancer. Int. J. Dev. Biol., 39: 737-757. PMID: 8645558

Kasparova, D. and T. Fait, 2009. [Early pregnancy loss and inherited thrombophilic states]. Ceska Gynekol., 74: 360-365. PMID: 20063840

Kujovich, J.L., 2004. Thrombophilia and pregnancy complications. Am. J. Obset. Gynecol., 191: 412-424. PMID: 15343215

Kupferminc, M.J. A. Eldor, N. Steinman, A. Many and A. Bar-Am et al., 1999. Increased frequency of genetic thrombophilia in women with complications of pregnancy. N. Engl. J. Med., 340: 9-13. PMID: 9878639

Kutteh, W.H., V.M. Park and S.R. Deitcher, 1998. Hypercoagulable state mutation analysis in white patients with early first-trimester recurrent pregnancy loss. Fertile. Steril, 71: 1048-1053. PMID: 10360908
Lindhoff-Last, E. and B. Luxembourg, 2008. Evidencebased indications for thrombophilia screening. Vasa., 37: 19-30. PMID: 18512539

Mohamed, M.A., M.A. El Moaty, A.F. El Kholy, S.A. Mohamed and A.I. Ali, 2010. Thrombophilic gene mutations in women with repeated spontaneous miscarriage. Genetic Test. Mol. Biomarkers, 14: 593-597. DOI: 10.1089/gtmb.2010.0052

Mukhopadhyay, R., K.N. Saraswathy and P.K. Ghosh, 2009. MTHFR C677T and factor V Leiden in recurrent pregnancy loss: a study among an endogamous group in North India. Genet Test Mol Biomarkers, 13: 861-865. PMID: 19839754

Pauer, H.U., J. Neesen and B. Hinney, 1998. Factor V Leiden and its relevance in patients with recurrent abortions. Am. J. Obstet. Gynecol., 178: 629. PMID: 9539549

Qublan, H.S., H.Y. Malkawi, Y.A. Tahat, S. Areidah and B. Nusair et al., 2005. In-vitro fertilisation treatment: factors affecting its results and outcome. J. Obstet. Gynaecol., 25: 689-693. PMID: 16263545

Qublan, H.S., S.S. Eid, H.A. Ababneh, Z.O. Amarin and A.Z. Smadi et al., 2006. Acquired and inherited thrombophilia: Implication in recurrent IVF and embryo transfer failure. Human Reprod., 21: 2694-2698. DOI: 10.1093/humrep/del203

Rey, E., S.R. Kahn, M. David and I. Shrier, 2003. Thrombophilic disorders and fetal loss: A metaanalysis. Lancet, 361: 901-908. PMID: 12648968

Unfried, G., A. Griesmacher, W. Weismuller, J.C. Huber and C.B. Tempfer, 2002. The C677T polymorphism of the methylenetetrahydrofolate reductase gene and idiopathic recurrent miscarriage. Obstet Gynecol, 99: 614-619. DOI: 10.1016/S0029-7844(01)01789-6

Vora, S., S. Shetty, M. Khare and K. Ghosh, 2009. Placental histomorphology in unexplained foetal loss with thrombophilia. Indian J. Med. Res., 129: 144-149. PMID: 19293440 